\title{
An Uncommon Cause of Splenomegaly
}

\author{
Biswajit Dey $^{1 *}$, Jyotsna Naresh Bharti ${ }^{1}$, Richa Gupta ${ }^{1}$, Tejinder Singh ${ }^{1}$, Nita Khurana ${ }^{1}$
}

1. Department of Pathology, Maulana Azad Medical College, India

* Corresponding Author:

Biswajit Dey, MD

Maulana Azad Medical College, India

Tel: +918754845398

Fax: 03192234635

Email: drbish25@rediffmail.com

Received: 16 Sep. 2015

Accepted: 11 Jan. 2016
Please cite this paper as:

Dey B, Bharti JN, Gupta R, Singh T, Khurana N. An Uncommon Cause of Splenomegaly. Middle East J Dig Dis 2016;8:150-153. DOI :10.15171/mejdd.2016.22

A 55-year-old man presented with pain in the left flank for the last 8 months with history of significant weight loss. The pain was relieved on assuming a knee-chest position. On clinical examination the patient was afebrile with mild tenderness in the left hypochondrium. There was no icterus or lymphadenopathy. The spleen was palpable $6 \mathrm{~cm}$ below the costal margin and was firm and non-tender. There was no hepatomegaly and thorough clinical examination failed to reveal any lymphadenopathy.

Baseline hematological investigations were $(\mathrm{Hb}=11.6 \mathrm{gm} / \mathrm{dl}, \mathrm{WBC}=8000 /$ cumm and a differential count of $64 \%$ neutrophils, 30\% lymphocytes, $3 \%$ eosinophils and $3 \%$ monocytes, platelet count $150 \times 10^{3} \mathrm{~mm}^{3}$. His erythrocyte sedimentation rate (ESR) was elevated with $52 \mathrm{~mm}$ at the end of the first hour. Liver function tests and renal function tests were within normal limits. His chest radiograph was within normal limits. Abdominal ultrasonograghy (USG) revealed an enlarged spleen measuring $20 \times 15 \mathrm{~cm}$ with multiple hypoechoic lesions. An abdominal computed tomography (CT) revealed a hypodense splenic mass with multiple splenic hilar lymphadenopathies. His chest radiographs, abdominal USG, and CT did not reveal any other lymphadenopathy. Based on radiological findings, a provisional diagnosis of a malignant tumour possibly primary lymphoma of spleen was made. A bone marrow examination was done, which revealed a normal study.

The patient underwent splenectomy with splenic hilar lymphadenectomy. The spleen along with the hilar lymph nodes was sent for histopathological examination. The specimen measured $23 \times 16 \times 10 \mathrm{~cm}$ and weighed $2 \mathrm{~kg}$. Grossly the capsule of the spleen was intact. Cut surface revealed a nodular grayish-white infiltrative growth measuring $21 \times 10 \times 9 \mathrm{~cm}$ almost replacing the whole of the spleen (figure 1a). The growth had fish-flesh like appearance with areas of necrosis. Sections examined from the growth showed dispersed population of malignant cells present in sheets (figure 1b). The cells had high nucleo-cytoplasmic ratio, vesicular nuclei and single or multiple prominent nucleoli. Mitotic count was 6 per 10 hpf with many atypical mitosis seen. Scattered mature lymphocytes were present in the background of the tumor. Tumor cells were seen to infiltrate surrounding white pulp. However, the capsule was intact. Large areas of necrosis were also seen. On immunohistochemistry the tumor cells were positive for LCA and B-cell marker (CD20) (figures $1 \mathrm{c}$ and $1 \mathrm{~d})$ and negative for T-cell marker (CD45RO) and BCL-2 (fiures 1e 


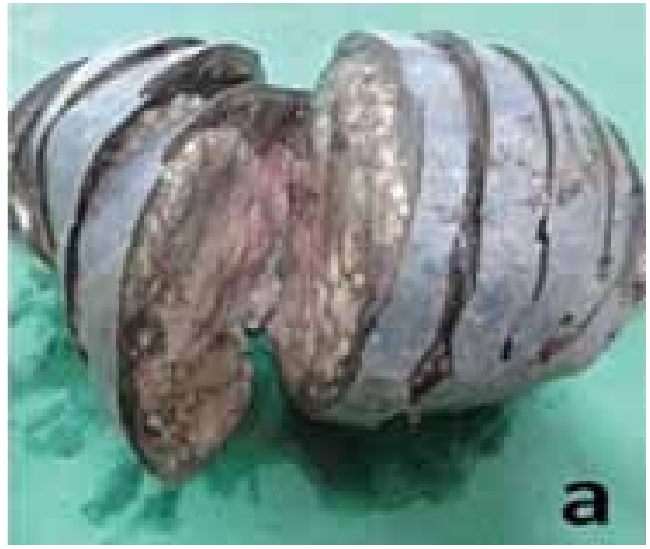

Fig.1a: Splenectomy measuring 23x16x10 cm with intact capsule. Cut surface shows nodular grayish-white infiltrative rowth almost replacing whole of spleen.

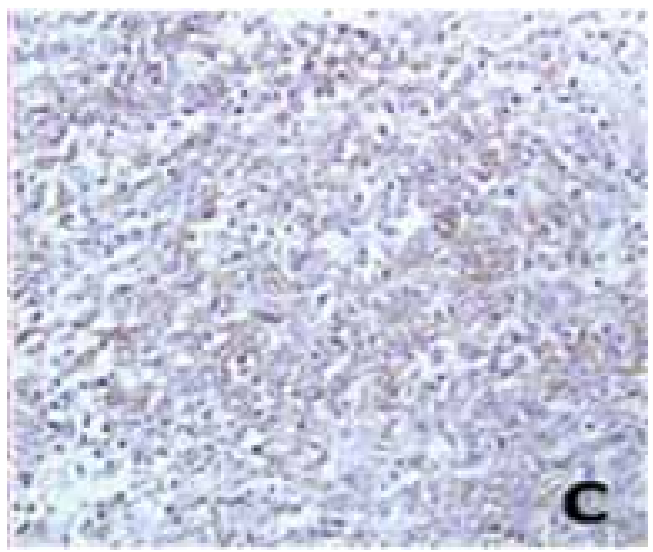

Fig.1c and 1d: Tumor cells are positive for LCA and CD20.

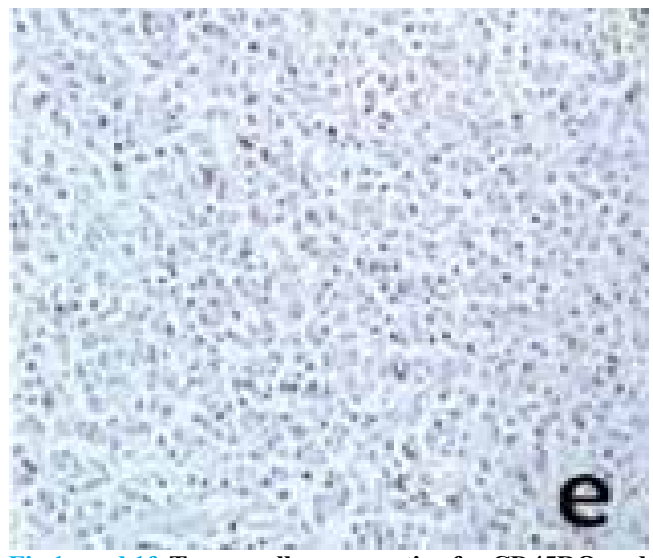

Fig.1e and 1f: Tumor cells are negative for CD45RO and BCl-2.

and 1f). The scattered small lymphocytes in the background were positive with $\mathrm{T}$ cell marker. Sections from red pulp showed congestion of sinusoids. Four lymph nodes were identified at the hilum of the spleen out of which two were involved.

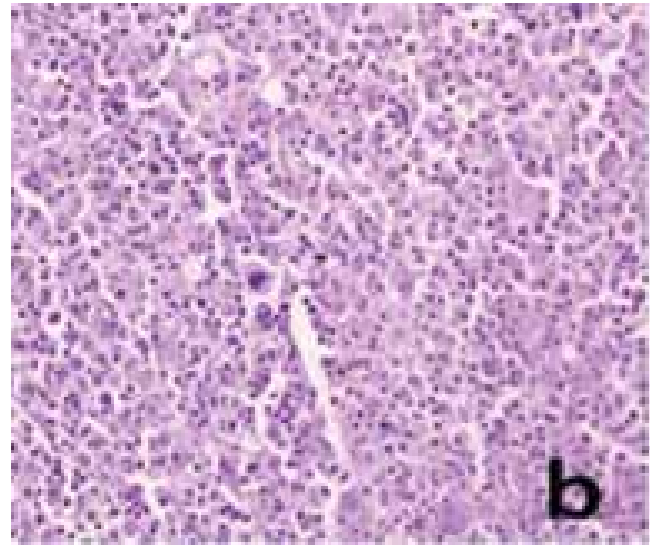

Fig.1b: Dispersed population of malignant cells present in sheets $(\mathrm{H} \& \mathrm{E}, 40 \mathrm{x})$.
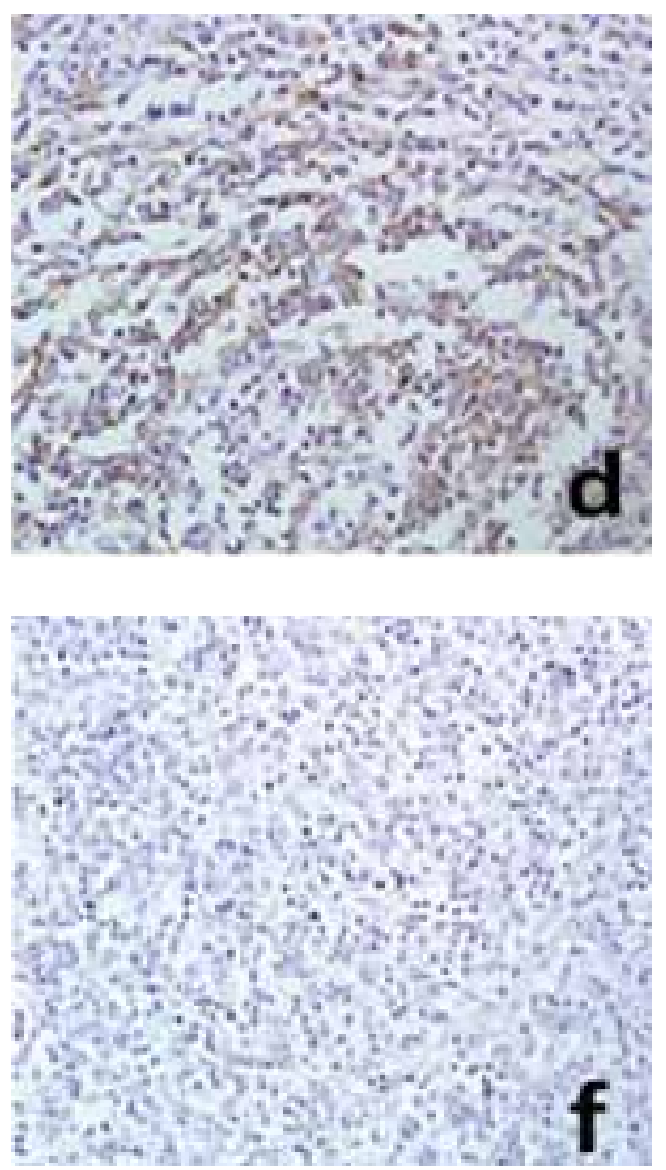

What is your diagnosis?

Answer:

Primary Diffuse large B-cell lymphoma (DLBCL) of the spleen (Ahmann stage 2) 


\section{DISCUSSION}

Tumours of the spleen are rare. The tumors of the spleen have been classified into benign (cysts, haemangiomas, littoral cell angioma, and lymphangioma) and malignant (lymphoma, metastases, and haemagiosarcoma). Primary malignancies are extremely rare with lymphoma being the most common splenic malignancy. ${ }^{1}$ Primary splenic lymphoma (PSL) is a rare tumor with an overall incidence of less than $1 \%$ of the tumors occurring in the spleen. It has been defined ambiguously in the literature leading to inaccurate estimation of its true incidence. ${ }^{2}$ Diffuse large B-cell lymphoma (DLBCL) is the most common lymphoma in the spleen accounting for $22-33 \%$ of the cases and a relatively favourable prognosis. ${ }^{3}$ Splenomegaly is the most common finding but it may be absent in a significant percentage of patients with lymphoma. ${ }^{1}$

The presenting symptoms of PSL are fever, generalized weakness, weight loss, and left hypochondriac discomfort and pain from splenomegaly. The important laboratory findings of PSL are cytopenia, elevated level of ESR, or $\beta 2$-microglobulin level. ${ }^{4}$ In the present case, the patient had splenomegaly and an elevated ESR.

The definition of PSL is quite ambiguous. Dasgupta et al defined PSL as lymphoma involving the spleen only along with involvement of lymph nodes confined to the splenic hilum. According to them there should be at least 6 months relapse-free period after splenectomy. ${ }^{5}$ The definition provided by Dasgupta et al is quite restrictive. Kehoe et al stated that the cases of Dasgupta et al defined early and localized diseases. These conditions did not take into account other patients with PSL in advanced phase of disease or diseases which were diagnosed late. ${ }^{6}$ According to Skarin et al diagnosis of PSL can be made if in any lymphoma, and splenomegaly is the predominant feature. ${ }^{7}$ Whereas Kraemer et al suggested that the diagnosis of PSL is reserved for patients with splenomegaly and cytopenia of at least two hematopoietic cell lines with no peripheral adenopathy. ${ }^{8}$ In our patient, lymphoma was confined to the spleen presenting as splenomegaly with involvement of the splenic hilar lymph nodes. Thus, the case fits into the definitions of PSL as provided by Dasgupta et al and Skarin et al.

In view of so many ambiguous definitions of PSL, it has been proposed to adopt the Ahmann et al's staging. ${ }^{9}$ They have arbitrarily divided the patients with PSL into three stages as stage 1 (tumor limited to spleen), stage 2 (involvement of splenic hilar lymph nodes as well), and stage 3 (involvement of liver or lymph nodes beyond the splenic hilum). ${ }^{9}$ Patients of stage 1 and stage 2 have a relatively better prognosis as compared with patients in stage 3 . In the present case, the patient was staged at Ahmann's stage 1 .

Although there is no consensus regarding the best treatment modality for PSL, splenectomy is the treatment of choice. Splenectomy also has a diagnostic and confirmatory role. ${ }^{4,7}$ In the present case, splenectomy was performed with dual objectives of diagnosis and therapy. The other treatment modalities include local radiation therapy and chemotherapy. ${ }^{4}$

PSL is a rare tumour and is an uncommon cause of splenomegaly. Primary splenic DLBCL is most common subtype of PSL; however, an early diagnosis is solicited since early stage has a favorable prognosis if appropriately treated.

\section{CONFLICT OF INTEREST}

The authors declare no conflict of interest related to this work.

\section{REFERENCES}

1. Giovagnoni A, Giorgi C, Goteri G. Tumours of the spleen. Cancer Imaging 2005;5:73-7.

2. Gobbi PG, Grignani GE, Pozzetti U, Bertoloni D, Pieresca $\mathrm{C}$, Montagna $\mathrm{G}$ et al. Primary splenic lymphoma: Does it exist? Haematologica 1994;79:286-93.

3. Grosskreutz C, Troy K, Cuttner J. Primary splenic lymphoma: report of 10 cases using the REAL classification. Cancer Invest 2002;20:749-53.

4. Kim JK, Hahn JS, Kim GE, Yang WI. Three cases of diffuse large B-Cell lymphoma presenting as primary splenic lymphoma. Yonsei Med J 2005;46:703-9. doi:10.3349/ ymj.2005.46.5.703

5. Dasgupta T, Coombes BC, Brasfield RD. Primary malignant neoplasms of the spleen. Surg Gynecol Obstet 1965;120:947-60.

6. Kehoe J, Straus DJ. Primary lymphoma of the spleen-clinical features and outcome after splenectomy. Cancer 1988;62:1433-8. doi: 10.1002/10970142(19881001)62:7<1433 :AID-CNCR 2820620731>3. 0. $\mathrm{CO} ; 2-\mathrm{V}$ 
7. Skarin AT, Davey FR, Moloney WC. Lymphosarcoma of the spleen. Results of diagnostic splenectomy in 11 patients. Arch Intern Med 1971;127:259-65. doi:10.1001/ archinte.1971.00310140087011.

8. Kraemer BB, Osborne BM, Butler JJ. Primary splenic presentation of malignant lymphoma and related disorders. A study of 49 cases. Cancer 1984;54:1606-19. doi:10.1002/1097-0142(19841015)54:8<1606:AIDCNCR2820540823>3.0.CO;2-5

9. Ahmann DL, Kiely JM, Harison EG, Paine WS. Malignant lymphoma of the spleen. Cancer 1966;19:461-9 